\title{
Would primary health care workers give appropriate dietary advice after cholesterol screening?
}

\author{
Jan Francis, Monica Roche, David Mant, Lesley Jones, Elaine Fullard
}

Oxford Prevention of Heart Attack and Stroke Project, Radcliffe Infirmary, Oxford OX2 6HE

Jan Francis, BSC, community dietitian

Elaine Fullard, RHV, project director

University of Oxford, Imperial Cancer Research Fund General Practice

Research Unit,

Department of Community

Medicine and General

Practice, Radcliffe

Infirmary, Oxford

OX2 6HE

Monica Roche, $\mathrm{MB}$, senior registrar

David Mant, MRCGP, clinical lecturer in general practice Lesley Jones, MSC, computer scientist

Correspondence to: Dr Roche.

\begin{abstract}
The purpose of this study was to obtain information on the dietary knowledge of primary health care workers and on their ability to apply this knowledge in practice. A total of 128 primary health care workers ( 53 general practitioners and 61 nurses) in 12 practices and 14 primary care facilitators were surveyed by questionnaire between December 1987 and June 1988. All of the practices were participating in a project to promote prevention in primary care and offered health checks designed to identify and deal with cardiovascular risk factors. The questionnaire focused on issues related to managing patients with moderate hypercholesterolaemia. The results of the study showed some important gaps in the health workers' knowledge - for example, only 91 understood that dietary intake of polyunsaturated fatty acids as a proportion of total fat intake should be increased in a diet designed to reduce serum lipid concentrations. Appreciable gaps in their ability to give practical and appropriate dietary advice were also identified: $\mathbf{3 5}$ gave advice that would have led to the patient losing weight (although his history indicated that he was not overweight), and 27 gave only negative advice, offering no suggestions about substituting healthy foods for unhealthy ones.

The demand for primary health care workers to give dietary advice. is increasing and is likely to increase further if a national screening programme for hypercholesterolaemia is recommended. The results of this survey point to a need for improved nutritional education and training in dietary counselling for general practitioners, nurses, and primary care facilitators.
\end{abstract}

\section{Introduction}

Since the beginning of the 1980 s several major reports on nutrition and health have emphasised the need for the British public to change their eating habits to reduce the incidence of diseases related to diet, especially coronary heart disease..$^{1.3}$ These reports have all recommended that health workers should participate in identifying and helping those in need of dietary advice. General practitioners and other primary health care workers are ideally placed for such work as about $70 \%$ of the public visits their general practitioner each year. ${ }^{+}$The public welcomes the participation of general practitioners in activities to promote health ${ }^{5}$ and trusts their advice. ${ }^{6}$ A previous study showed that primary health care teams are effective in persuading people to stop smoking, ${ }^{i}$ and it seems reasonable to assume that they might be effective in helping people to adopt healthier diets. Moreover, the expansion of the role of general practice in promoting health has been encouraged by a recent white paper. ${ }^{8}$
In Oxfordshire, as a result of the Oxford prevention of heart attack and stroke project, many local practices now offer health checks to their patients. ${ }^{9}$ These are designed to identify and deal with cardiovascular risk factors, and dietary advice often forms a part of intervention. The advice given should be appropriate and practical. Little is known, however, about the motivation or competence of primary health care workers to give such advice. The main purpose of our study was to survey the dietary knowledge of primary health care workers with particular emphasis on their ability to apply their knowledge in practice.

\section{Subjects and methods}

The survey was carried out between December 1987 and June 1988 by one of us (JF) in association with the Oxford prevention of heart attack and stroke project. Twelve practices were chosen randomly from the 40 practices in Oxfordshire that offered health checks. Two practices refused to participate (one because of building work at the surgery and one because a dietitian was visiting the surgery regularly and the doctors did not want any further input), and these were replaced.

A questionnaire was devised to test both the health workers' knowledge of the principles of healthy eating (that is, their understanding of the principles stated in reports of the National Advisory Committee on Nutrition Education and the Committee on Medical Aspects of Food Policy) and their ability to apply this knowledge. Their practical abilities were tested by their response to a brief case history of a middle aged man with moderate hypercholesterolaemia (box): they were asked to indicate the three most important questions they would have liked to ask the patient to clarify his dietary history and the six most important pieces of advice they would give him to modify his diet appropriately. They were also asked a sample of practical questions asked commonly by patients.

One primary health care worker at each surgery was asked to distribute the questionnaires to all those concerned with giving dietary advice; the questionnaires were collected by the project dietitian at the start of a practice meeting, and the issues raised were discussed. Completed questionnaires were received from 53 general practitioners and 61 nurses (24 practice nurses, 18 district nurses, and 19 health visitors), giving a rate of response of $74 \%$ for nurses and $80 \%$ for general practitioners. Most respondents (58 (95\%) nurses and $47(89 \%)$ doctors) said that they gave dietary advice as part of general promotion of health at least once a week.

Questionnaires were distributed separately to a British group of 14 primary care facilitators attending an introductory training course in Oxford (all of whom returned a completed questionnaire). The facilitators 


\section{Case history used to assess the ability of primary health care workers to apply their dietary knowledge}

The patient is a 54 year old factory worker. He attended for a health check last week and was found to have a moderately raised cholesterol concentration $(6.8 \mathrm{mmol} / \mathrm{l})$. Triglyceride concentrations are within normal limits. He is not overweight. You have asked to see him at the surgery and are spending time discussing his diet.

You elicit a brief dietary history, which you sketch out as follows (for an average day):

700 am Cornflakes, toast, tea

10 00am Sandwich (bacon, egg, or cheese), tea

Noon More sandwiches, cake, tea

$300 \mathrm{pm}$ Tea, chocolate bar

$600 \mathrm{pm}$ Meat (roast or chops or sausage, etc)

Potatoes (boiled or mashed) and vegetables or "fry up" and chips

1000 pm Coffee

Pudding or pie and custard or ice cream

Couple of pints of beer at the weekend

QUESTIONS

You need to fill in a few details. Can you suggest three further dietary questions you might ask? If you think of more than three, choose the three you think are most important.

Can you suggest six pieces of practical advice the patient must have? If you can think of more than six, choose the six you think are most important.

TABLE I-Foods that primary health care workers would most commonly ask about type and quantity consumed to clarify dietary history of patient (see box). Figures are nambers (percentages) of primary health care workers

\begin{tabular}{lccccc}
\hline & $\begin{array}{c}\text { General } \\
\text { practitioners } \\
(\mathbf{n}=53)\end{array}$ & $\begin{array}{c}\text { Nurses } \\
(\mathbf{n}=61)\end{array}$ & $\begin{array}{c}\text { Facilitators } \\
(\mathbf{n}=14)\end{array}$ & $\begin{array}{c}\text { Total } \\
(\mathbf{n}=128)\end{array}$ & $\begin{array}{c}95 \% \text { Confidence } \\
\text { interval } \\
(\%)\end{array}$ \\
\hline Spreads and cooking oils & $26(49)$ & $36(59)$ & $10(71)$ & $72(56)$ & 47 to 65 \\
Milk & $20(38)$ & $28(46)$ & $7(50)$ & $55(43)$ & 34 to 52 \\
Bread & $13(25)$ & $20(33)$ & $5(36)$ & $38(30)$ & 22 to 38 \\
Sugar & $14(26)$ & $9(15)$ & $5(36)$ & $28(22)$ & 15 to 29 \\
Fruit and vegetables & $10(19)$ & $10(16)$ & $2(14)$ & $22(17)$ & 10 to 24 \\
Meat & $7(13)$ & $5(8)$ & $3(21)$ & $15(12)$ & 6 to 18 \\
Cheese & $3(6)$ & $6(10)$ & $1(7)$ & $10(8)$ & 3 to 13 \\
\hline
\end{tabular}

TABLE II -Subjects on which primary health care workers would most commonly advise patient whose case history is given in box. Figures are numbers (percentages)

\begin{tabular}{lccccc}
\hline & $\begin{array}{c}\text { General } \\
\text { practitioners } \\
(\mathrm{n}=53)\end{array}$ & $\begin{array}{c}\text { Nurses } \\
(\mathrm{n}=61)\end{array}$ & $\begin{array}{c}\text { Facilitators } \\
(\mathrm{n}=14)\end{array}$ & $\begin{array}{c}\text { Total } \\
(\mathrm{n}=128)\end{array}$ & $\begin{array}{c}95 \% \text { Confidence } \\
\text { interval } \\
(\%)\end{array}$ \\
\hline Cooking methods & $34(64)$ & $41(67)$ & $12(86)$ & $87(68)$ & 601076 \\
Spreads and oils & $28(53)$ & $37(61)$ & $11(79)$ & $76(59)$ & 50 to 68 \\
Fruit and vegetables & $27(51)$ & $39(64)$ & $9(64)$ & $75(59)$ & 50 to 68 \\
Meat & $32(60)$ & $33(54)$ & $8(57)$ & $73(57)$ & 48 to 56 \\
Milk & $17(32)$ & $28(46)$ & $10(71)$ & $55(43)$ & 34 to 52 \\
Fibre & $21(40)$ & $22(36)$ & $7(50)$ & $50(39)$ & 31 to 47 \\
\hline
\end{tabular}

TAB̂LE III - Number (percentage) of primary health care workers who recommended use of various brands of oils and spreads as part of diet designed to reduce serum concentrations of cholesterol

\begin{tabular}{lccccc}
\hline & $\begin{array}{c}\text { General } \\
\text { practitioners } \\
(\mathbf{n}=53)\end{array}$ & $\begin{array}{c}\text { Nurses } \\
(\mathbf{n}=61)\end{array}$ & $\begin{array}{c}\text { Facilitators } \\
(\mathbf{n}=14)\end{array}$ & $\begin{array}{c}\text { Total } \\
(\mathbf{n}=128)\end{array}$ & $\begin{array}{c}95 \% \text { Confidence } \\
\text { interval } \\
(\%)\end{array}$ \\
\hline Oils: & & & & & \\
$\quad$ Corn & & & & & \\
$\quad$ Olive & & & & & \\
$\quad$ Own brand vegetable & $37(70)$ & $46(75)$ & $10(71)$ & $93(73)$ & 65 to 81 \\
Spreads: & $9(17)$ & $32(52)$ & $8(57)$ & $74(58)$ & 49 to 67 \\
$\quad$ Flora & $20(33)$ & $3(21)$ & $32(25)$ & 17 to 33 \\
$\quad$ St Ivel Gold & $50(94)$ & $57(93)$ & $14(100)$ & $121(95)$ & 91 to 99 \\
Own brand margarine & $21(40)$ & $37(61)$ & $8(57)$ & $66(52)$ & 43 to 61 \\
\hline
\end{tabular}

^Indicates products that should be recommended as part of a cholesterol lowering diet. all had a background in nursing and were responsible for introducing the Oxford system of health checks into general practices in other parts of the country.

\section{Results}

\section{CASE HISTORY}

Table I shows the seven commonest questions overall that the health workers would have liked to ask the patient and the proportion of each group of health workers asking each question. The differences between each group must be interpreted with caution as, with one exception, they were not significant. The most popular question was which type and what quantity of fat the patient used for cooking and spreading (asked by 72 health workers); which types and what quantities of milk and bread he consumed (asked by 55 and 38 of them respectively) were the next most popular questions. Perhaps surprisingly, the fourth commonest question was what quantity of sugar he consumed (asked by 28). By contrast, only 15 asked about consumption of meat and 10 about consumption of cheese. At least a quarter of all of the groups asked at least one question unrelated to the diet history (for example, about smoking or exercise).

The health workers were also asked to give six pieces of advice that the patient would need to modify his diet appropriately. Many were unable to do this, and about a third of all groups gave at least one piece of advice unrelated to the specific dietary issues. Table II shows the six pieces of advice given most commonly. At least half of the health workers advised a change in method of cooking; a change in the type of fat used for cooking or spreading, or both; a change from red to white meat; and increased consumption of fruit and vegetables. Advice about changing to skimmed or semiskimmed milk was also given commonly, although by only 17 (32\%) general practitioners compared with $28(46 \%)$ nurses and $10(71 \%)$ facilitators $\left(\chi^{2}=7 \cdot 36, \mathrm{p}<0.05\right)$. Surprisingly, 35 health workers gave advice that would have led to the patient losing weight, although the history stated clearly that he was not overweight. In addition, 78 gave at least one piece of advice that was likely to mislead or confuse (for example, to eat less bread), and 27 gave only negative advice and made no suggestions about substituting healthy foods for unhealthy ones.

\section{COMMON QUERIES}

Questions were asked to test the ability of the health workers to deal with specific queries about the right sort of oils and spreads to use. Table III gives the results by group of health workers. Most of them were able to recommend correctly the use of corn oil or olive oil, and most in all of the groups recommended correctly that patients use Flora margarine. Although most health workers understood that supermarkets' own brands of cooking oil should not be recommended, almost half of the general practitioners and over half of the nurses and facilitators recommended own brand margarine. Specific questions were also asked about the relative fat content of common brands of products. Once again this showed their lack of detailed practical knowledge. Overall, the number who answered correctly (out of a choice of three options in each case) was 58 for snack foods, 65 for meat products, and 90 for dairy products.

\section{KNOWLEDGE OF HEALTH RECOMMENDATIONS}

Knowledge of the changes in dietary constituents recommended by the National Advisory Committee on Nutrition Education and the Committee on Medical Aspects of Food Policy was tested. Table IV gives the results of health workers. Most (over 90\%) of the health workers understood the need to reduce intake of 
TABI.E IV-Number (percentage) of primary health care workers who answered correctly questions about recommendations of National Advisory Committee on Nutrition Education and Committee on Medical Aspects of Food Policy for dietary change

\begin{tabular}{lccccc}
\hline & $\begin{array}{c}\text { General } \\
\text { practitioners } \\
(\mathbf{n}=53)\end{array}$ & $\begin{array}{c}\text { Nurses } \\
(\mathbf{n}=61)\end{array}$ & $\begin{array}{c}\text { Facilitators } \\
(\mathbf{n}=14)\end{array}$ & $\begin{array}{c}\text { Total } \\
(\mathbf{n}=128)\end{array}$ & $\begin{array}{c}95 \% \text { Confidence } \\
\text { intervals } \\
(\%)\end{array}$ \\
\hline $\begin{array}{l}\text { Decrease recommended: } \\
\quad \text { Total fat }\end{array}$ & $50(94)$ & $57(93)$ & $14(100)$ & $121(95)$ & 91 to 99 \\
$\quad \begin{array}{l}\text { Saturated fat } \\
\text { Increase recommended: }\end{array}$ & $49(92)$ & $60(98)$ & $14(100)$ & $123(96)$ & 93 to 99 \\
$\quad \begin{array}{l}\text { Polyunsaturated fat } \\
\text { Fibre }\end{array}$ & $37(70)$ & $42(69)$ & $12(86)$ & $91(71)$ & 63 to 79 \\
$\quad$ Carbohydrate & $51(96)$ & $56(92)$ & $13(93)$ & $120(94)$ & 90 to 98 \\
& $5(9)$ & $5(8)$ & $5(36)$ & $15(12)$ & 6 to.18 \\
\hline
\end{tabular}

total fat and saturated fat. A supplementary question showed that most still believed dietary cholesterol to be the most important determinant of serum cholesterol concentrations in spite of the clear statements to the contrary by the Committee on Medical Aspects of Food Policy and the National Advisory Committee on Nutrition Education. There was some confusion about the role of polyunsaturated fats in the diet, although most (91) respondents answered correctly that intake of polyunsaturated fats as a proportion of all fat should be increased. The question on increasing fibre content in the diet was answered correctly by over $90 \%$ of them. The question on carbohydrate intake, however, was answered poorly, with only 15 understanding the need to replace energy from fat with energy from other sources, including carbohydrates.

\section{Discussion}

As the primary health care workers surveyed were already routinely concerned with giving advice to their patients on healthy eating and worked in practices that were participating in a project to promote prevention in primary care they may not have been typical in terms of knowledge or motivation. Even so, there were important gaps in their knowledge and in the skills needed to apply it.

Knowledge of some aspects of the recommendations of the National Advisory Committee on Nutrition Education and the Committee on Medical Aspects of Food Policy (for example, the need to decrease total fat and saturated fat intake and to increase fibre intake) was almost universal among the health workers. The importance of increasing the relative proportion of polyunsaturated fat in the diet and the role of dietary cholesterol were less well understood, which is worrying. Likewise, the message that reducing fat as a source of energy means replacing it with carbohydrate rich in fibre had not been understood.

There seemed to be even greater problems in applying knowledge. The ability to take a brief diet history that covers everything that is important is an obvious precondition to giving appropriate advice. An understanding of the contribution of various sources of fat to the total fat content of the diet should have directed the health workers to the most appropriate questions (that is, questions about types of oils and spreads, milk, meat, etc). These were the questions asked most commonly, but many of the health workers failed to ask them at all. In addition, many of the health workers were clearly unable to focus on the dietary issues relevant to the case provided and instead asked general dietary questions (for example, 28 asked about consumption of sugar) or questions about other behaviour related to health such as smoking.

Most of the health workers were able to give general advice for lowering serum lipid concentrations, although considerable numbers omitted vital advice (for example, only 28 (53\%) general practitioners suggested changing to oils and spreads high in polyunsaturated fats). Moreover, there was considerable difficulty in tailoring this general advice to the needs of a specific patient, in this case a manual worker of normal weight unlikely to benefit from, and certainly unlikely to stick to, a low energy diet. As with the history many of the health workers were unable to focus on specific dietary issues (that is, those related to lowering serum lipid concentrations) and instead gave general dietary advice (for example, to cut out sugar and salt) or general health advice. Of greater concern were the 78 health workers who gave advice likely to confuse or mislead patients.

This survey has shown some gaps in health workers' knowledge and some deficits in their ability to give dietary advice that is practical, is appropriate to the needs of the patient, and can be given in the limited time available for consultation. Similar results were reported for an earlier survey of general practitioners working in London..$^{10}$ The use of checklists (to prompt the correct questions) and standard diet sheets (outlining the elements of a diet aimed at reducing serum lipid concentrations) may enable primary care workers to be effective in spite of their deficiencies. The value of such an approach, however, is yet to be established, and a sizable proportion of patients would probably still require personalised dietary counselling. The demand for primary health care workers to give dietary advice is likely to increase if the standing medical advisory committee recommends a national screening programme for hypercholesterolaemia when it reports later this year. Extrapolation from the distribution of serum cholesterol concentrations in the population screened by Mann et al $l^{11}$ suggests that each general practitioner is likely to have 200 patients aged 25-59 who have a serum cholesterol concentration $>6.5 \mathrm{mmol} / \mathrm{l}$; this is the concentration at which advice on lowering serum lipid concentration is recommended..$^{12}$ A prerequisite of any screening programme is the ability to deal with any problems it uncovers. The results of this survey do not give cause for complacency. Clearly, improved nutritional education and training in dietary counselling of all primary health care workers are urgently needed. Community dietitians are trained for this, but at present there are too few of them to deal with this problem.

We thank all of the doctors, nurses, and facilitators who participated in this study for their cooperation. The study was supported by a research grant from Oxford Regional Health Authority.

1 Committee on Medical Aspects of Food Policy. Report of the panel on diet in relation to cardiovascular disease. London: HMSO, 1984.

2 National Advisory Committee on Nutrition Education. Proposals for nutritional guidelines for health education in Brituin. London: Health Education Council, 1983.

3 British Medical Association. Diet, nutrition and health. Report of the Board of Science and Education. London: BMA, 1986.

+ Royal College of General Practitioners, Office of Population Censuses and Survers, Department of Health and Social Security. 1981-82 Morbidity statistics from general practice. London: HMSO, 1986.

5 Wallace PG, Haines AP. General practitioners and health promotion: what patients think. Br Med f 1984;289:533-6.

6 Anonymous. "Which" survey of practice services. London: Consumer Association, 1987

7 Jamrozik K, Vessey M, Fowler GH, Wald N, Parker G, Van Vunakis H Controlled trial of three different anti-smoking interventions in general practice. Br Med f 1984;288:1499-503.

8 Department of Health and Social Security. Promoting better health: the government's programme for improving primary health care. London: $\mathrm{HMSO}$ 1987

9 Fullard EM, Fowler GH, Gray JAM. Promoting prevention in primary care: controlled trial of a low technology, low cost approach. $\mathrm{Br}$ Med $\mathcal{f}$ 1987;294:1080-2

10 Avenell A, Trehertz J, Tompkins A. Family doctors' knowledge of nutrition and coronary heart disease prevention. Proceedings of the thirteenth interand coronary heart disease prevention. Proceedings of the thirteen

11 Mann JI, Lewis B, Shepherd J, Winder AF, Fenster S, Rose L, Morgan B Blood lipid concentrations and other cardiovascular risk factors: distribution, prevalence, and detection in Britain. BrMed J 1988;296: 1702-6.

12 British Cardiac Society. Report of working group on coronary disease prevention. London: British Cardiac Society, 1987.

(Accepted 4 May 1989) 